\title{
The effect of oxygenate fuels on PN emissions from a highly boosted GDI engine
}

Felix CP Leach ${ }^{\mathrm{a}^{*}}$, Richard Stone ${ }^{\mathrm{a}}$, David Richardson ${ }^{\mathrm{b}}$, James WG Turner ${ }^{\mathrm{c}}$, Andrew Lewis ${ }^{c}$, Sam Akehurst ${ }^{c}$, Sarah Remmert ${ }^{d}$, Steven Campbell ${ }^{d}$, Roger Cracknell $^{\mathrm{d}}$

${ }^{a}$ Department of Engineering Science, University of Oxford, UK; ${ }^{b}$ Powertrain Research, Jaguar Land Rover, UK; ${ }^{c}$ Powertrain \& Vehicle Research Centre, University of Bath, UK; ${ }^{d}$ Shell Global Solutions, UK

*corresponding author: felix.leach@eng.ox.ac.uk

1 Abbreviations: AFR- Air Fuel Ratio, BMEP - Brake Mean Effective Pressure, BSPN Brake Specific Particle Number, DMS - Differential Mobility Spectrometer, DVPE - Dry Vapour Pressure Equivalent, EBP - Exhaust Back Pressure, EGR - Exhaust Gas Recirculation, GDI - Gasoline Direct Injection, GEM - Gasoline Ethanol and Methanol, KLSA - Knock Limited Spark Advance, NEDC - New European Drive Cycle, MON - Motor Octane Number, PM - Particulate Matter, PMP - Particle Measurement Protocol, PN Particle Number, RON - Research Octane Number, RVP - Reid Vapour Pressure, THC Total Hydrocarbon 


\section{The effect of oxygenate fuels on PN emissions from a highly boosted engine}

Gasoline Direct Injection (GDI) engines are increasingly available in the market. Such engines are known to emit more Particulate Matter (PM) than their port-fuel injected predecessors. There is also a widespread use of oxygenate fuels in the market, up to blends of E85, and their impact on PN emissions is widely studied. However the impact of oxygenate fuels on PN emissions from downsized, and hence highly-boosted engines is not known.

In this work, PN emissions from a highly boosted engine capable of running at up to 35 bar Brake Mean Effective Pressure (BMEP) have been measured from a baseline gasoline and three different oxygenate fuels (E20, E85, and GEM - a blend of gasoline, ethanol, and methanol) using a DMS500. The engine has been run at four different operating points, and a number of engine parameters relevant to highly-boosted engines (such as EGR, exhaust back pressure, and lambda) have been tested - the PN emissions and size distributions have been measured from all of these.

The results show that the oxygenate content of the fuel has a very large impact on its PN emissions, with E85 giving low levels of PN emissions across the operating range, and GEM giving very low and extremely high levels of PN emissions depending on operating point. These results have been analysed and related back to key fuel properties.

Keywords: PN; particulate; oxygenate; ethanol; methanol; GDI; gasoline; downsizing; boost

\section{Introduction}

Gasoline Direct Injection (GDI) engines have been widely adopted in the market, offering lower $\mathrm{CO}_{2}$ emissions than previous engine technologies, however they tend to emit more Particulate Matter (PM) emissions, particularly the total number of particles (PN) emitted [1]. Engine downsizing is essentially an extension of GDI technology - with reduced engine displacement, and hence throttling and friction losses. The power output is maintained by pressurising the inlet air using a super- or turbo-charger hence running at high Brake Mean 
Effective Pressures (BMEP). Such engines are becoming available in the market in greater numbers [2].

Particle number emissions from GDI engines generally follow a logbinormal distribution [3] with the smallest particles known as the nucleation mode (made up of mostly volatile and semi-volatile species) and larger particles known as the accumulation mode (generally made up of solid cores with adsorbed species). The particle mass contribution is dominated by the accumulation mode, with the nucleation mode having a minor effect on the mass emitted, as the largest particles have the highest mass. Such emissions have been well characterized [4], but only recently from GDI engines operating at high levels of boost [5].

\section{Oxygenate fuels}

Most of the interest in oxygenate compounds in fuels has focussed on ethanol. Ethanol (which can be made renewably and is thus also called a 'biofuel') is seen as a way of reducing net $\mathrm{CO}_{2}$ emissions from vehicles, and in low quantities can be a 'drop-in' component for straight gasoline.

In Europe, E5 (meaning a $5 \%$ by volume blend of ethanol in gasoline) is now common [6]; in the USA, blends of E10 are ubiquitous, and E15 is legal for sale as gasoline in 2001 model year vehicles and later [7].

Many of the features of physico-chemical properties of blends of ethanol with gasoline come from the different intermolecular forces between ethanol molecules, as compared to hydrocarbons. In particular the presence of the -OH group means that hydrogen bonding can occur between ethanol molecules, whereas, hydrocarbon molecules interact with each other principally via dispersion (van der Waal's) forces. Specific consequences of this are: 
1. Because of the non-ideal mixing, the vapour pressure of hydrocarbon/ethanol mixtures is higher than would be predicted by Raoult's law. This can pose challenges in meeting Dry Vapour Pressure Equivalent (DVPE) specifications [8]

2. The mixtures also tend to display azeotropic behaviour, so that the boiling point of a hydrocarbon/ethanol mixture can be lower than the final boiling point of the hydrocarbon base fuel [9].

3. Because of the hydrogen bonding, ethanol has a much higher enthalpy of vaporization than the hydrocarbon base fuel. This will lead to a much more extensive cooling of the spray during the process of droplet breakup, than would occur in the absence of ethanol. Ethanol also has a much lower volumetric energy density compared with gasoline. This means that on an equivalent cycle using a high ethanol content fuel, a higher volume of fuel will need to be injected. Therefore there will be more fuel spray to evaporate, and it will not evaporate as quickly as a result of ethanol's high enthalpy of vaporisation and low energy density, possibly leading to residual rich regions.

The factors listed above are likely to have competing effects on the ease with which the spray evaporates, and the likelihood of rich combustion zones which could lead to the formation of soot. Additionally, the presence of fuel-bound oxygen is likely to favour a more rapid oxidation of any soot-precursor molecules

It is not surprising therefore that some studies have found that under certain conditions, the presence of ethanol in fuel can increase particulate emissions. [10], while other studies have shown the opposite effect $[11,12,13,14]$ - a reduction in PN emissions with increasing levels of ethanol. 
Overall the biggest impact comes from combustion system geometry, where, provided you can avoid fuel impingement on combustion system surfaces, the presence of ethanol would be expected to decrease PN emissions. The presence of deposits on injector tips may also change spray behaviour, leading to more impingement and impact particulate creation [15]. If impingement does occur, then the poor evaporation of ethanol resulting from the high heat of vaporization may dominate leading to an increase in PN emissions (see Table 1).

Table 1 shows the enthalpy of vaporisation and volumetric energy density of gasoline, ethanol, and methanol.

Table 1: Enthalpies of vaporisation and lower heating values of gasoline, ethanol, and methanol

\begin{tabular}{lrrr}
\hline & $\Delta \boldsymbol{H}_{\boldsymbol{v a p}}(\mathrm{kJ} / \mathrm{mol})$ & $\begin{array}{r}\Delta \boldsymbol{H}_{\boldsymbol{v a p}}(\mathrm{kJ} / \mathrm{kg} \\
\text { stoichiometric } \\
\text { mixture })\end{array}$ & $\mathrm{LHV}(\mathrm{MJ} / \mathrm{L})$ \\
\hline Gasoline (representative) & 35.4 & 20 & 31.3 \\
Ethanol & 47.9 & 92 & 21.2 \\
Methanol & 38.3 & 159 & 17.9 \\
\hline
\end{tabular}

Sources: $[4,16,17,18]$

It has previously been noted [19] that Air-Fuel-Ratios rich of stoichiometric increase particulate emissions. This is true of ethanol, but the increase in PM emissions rich of stoichiometric for ethanol is very small and, compared to gasoline, is in reality a dramatic reduction in particulate emissions at all load points (E10 showing a greater than order of magnitude reduction in PM emissions compared with straight gasoline in Chen et al. [20]) [21]. This reduction is thought to be due to the fact that the presence of oxygen in the fuel molecule reduces the concentration of important intermediate species that promote formation of soot precursors [21, 22]. 
The effect of ethanol on particulate emissions is therefore mixed, depending on the stoichiometry, level of ethanol, and combustion system geometry. A smaller increase in PM emissions at lower levels of ethanol due to evaporative performance can be seen at stoichiometric and lean conditions, but a large decrease (relative to gasoline) at rich conditions. In general high levels of ethanol (say E85) lead to a large decrease in PM emissions.

Whilst most of the research into the effect of oxygenate components in fuel on particulate emissions has focused on ethanol, other oxygenates added to fuel include methanol, which is particularly the case in China, as well as potentially a combination of components such as in gasoline, ethanol, and methanol (GEM) blends.

\section{GEM fuels}

GEM blends have been shown to be a possible drop-in alternative to high ethanol gasoline blends such as E85 [23, 24, 25, 26]. Their drop-in nature (i.e. requiring no calibration changes on a vehicle capable of taking E85) is achieved by blending them to be isostoichiometric (i.e. having the same stoichiometric air-fuel ratio) with E85, and this also achieves the same latent heat, volumetric energy content, and octane number [26]. This potential is true of any GEM fuel blended to target the stoichiometry of a binary gasolineethanol blend. The desirability of GEM fuels is based around the ability of methanol to be mass produced from a carbonaceous base - avoiding the "biomass limit" concerns around ethanol [27]. Ultimately some researchers have suggested that methanol could be synthesized from $\mathrm{CO}_{2}$ using renewable electricity leading to a renewable liquid fuel [28]. Using GEM fuels as a drop-in for E85 in such circumstances would be a very fast way of significantly decarbonising the existing vehicle fleet. 
However other studies have noted that methanol and GEM fuels degrade vehicle fuel system seals and can corrode some metals [29]. An increase in aldehyde emissions has also been noted with Methanol fuels [30] as well as an increase in THC emissions [31]. Other studies have noted that an increase in methanol use could lead to an increase in $\mathrm{CO}_{2}$ emissions (due to its synthesis from coal and natural gas) and there are other concerns about its unregulated use, particularly in China [32].

The effect of such GEM blends on PM emissions is expected to be similar to that of ethanol, making an allowance for their different vapour pressures, and evaporative performance. In other words, with reference to Table 1, a slight increase in PM emissions might be expected from blends containing methanol due to its higher $\Delta \boldsymbol{H}_{\boldsymbol{v a p}}(\mathrm{kJ} / \mathrm{kg}$ stoichiometric mixture). However a slight decrease in PM emissions might be expected due to methanol's lower sooting tendency compared to ethanol [33] so again, like ethanol, the effect of methanol on PM emissions is mixed and dependent on combustion system.

Given the increasing penetration of oxygenate fuels in the market, and the increase in the use of highly boosted GDI engines it is clearly of interest to measure the PN emissions from such engines fueled by these fuels. Both ethanol and methanol have higher RON than standard gasoline so their use in highly-boosted engines is likely to be of benefit because of increased knock resistance [34]. The formation mechanisms of PM emissions from boosted engines are not different from their naturally-aspirated counterparts. Higher cylinder compression temperatures should promote spray evaporation, even with fuels with high $\Delta \boldsymbol{H}_{\text {vap }}$ and hence reduce wall wetting and reduce PN emissions. However, this has not been investigated in the literature. 


\section{Experimental methodology}

In this work PN emissions from a 2.0 L engine [35] at very high levels of boosting have been measured using a Cambustion DMS500 in order to evaluate the effect of three oxygenated fuels on PN emissions compared to those from a baseline gasoline at such extreme conditions.

\section{Engine}

A comprehensive outline of the highly boosted engine, known as Ultraboost, has been given by Turner et al. [35]. Details of the Ultraboost engine in its 'UB100' specification as used here are given in Table 2. In the work reported here the engine is not fitted with a turbocharger or a supercharger; instead inlet air and exhaust pressure (and temperature) control is achieved via an external boosting rig.

Table 2: Specifications of the Ultraboost UB100 engine used in this work

\begin{tabular}{ll}
\hline Type & Inline 4 cylinder \\
Bore $\times$ Stroke & $83 \times 92 \mathrm{~mm}$ \\
Displacement & $1991 \mathrm{~cm}^{3}$ \\
Valves per cylinder & 2 intake, 2 exhaust \\
Compression ratio & $9: 1$ \\
Maximum fuel pressure & $200 \mathrm{bar}$ \\
Peak BMEP & $35 \mathrm{bar}$ \\
Peak cylinder pressure & $150 \mathrm{bar}$ \\
\hline
\end{tabular}

\section{Instrumentation}

A Cambustion DMS500 (DMS) was used to measure the particulate emissions from this engine. The DMS has been fully described in Reavell et al. [36] and uses electrical charge to drag ratio to measure particle size and number distributions. The results from this DMS using this sampling methodology have been shown to represent the legislatively compliant European PMP test procedure results closely [37]. The sampling and analysis methods used with the DMS in this work have been comprehensively described in [5] but are summarized 
here for convenience. Due to the very small accumulation mode particles observed, simply using the standard DMS fitting software was not a reliable method. Hence the particle spectra were filtered digitally by a Wiebe function designed to mimic the European PMP test procedure. The sample is taken approximately $3 \mathrm{~m}$ downstream of a pulse separated, watercooled exhaust manifold and downstream of an exhaust back pressure valve (used to mimic the pressure drop associated with a turbocharger). The sample is taken by a remote cyclone (where it is diluted at a ratio of 10:1) and passed through a heated sample line - both maintained at $150^{\circ} \mathrm{C}$. No further dilution takes place prior to the sample passing into the classifier column. Throughout this paper, particle diameters reported are derived from the DMS, and are electrical mobility diameters.

\section{Engine test points}

The tests were run as a large experimental matrix, shown in Table 3 and Figure 1. This matrix covered a large portion of the engine map including a New European Drive Cycle (NEDC) minimap point (1250 rpm / 3.77 bar BMEP) and a full load curve at three engine speeds $(2000,3000$, and $4000 \mathrm{rpm})$. As the aim was to examine the effects of extremely highly boosted engine operating conditions the full load points were of particular interest, and the minimap point more of a "validation" against existing engines. The maximum BMEP at full load was limited by knock and maximum cylinder pressure $\left(\mathrm{P}_{\max }\right)$. The loads achieved at each point are shown in Table 4, this load corresponds to the load achieved for the results in Figure 2, Figure 4, Figure 6, and Figure 8.

\section{Table 3: Experimental test points}

\begin{tabular}{|c|c|c|c|c|c|c|c|}
\hline Test point & $\begin{array}{l}\text { Speed } \\
(\text { rpm) }\end{array}$ & $\begin{array}{r}\text { Inlet Air T } \\
\left({ }^{\circ} \mathbf{C}\right) \\
\end{array}$ & $\begin{array}{r}\text { EBP } \\
(\mathrm{kPaG})\end{array}$ & $\lambda$ & $\begin{array}{r}P_{\text {inj }} \\
\text { (bar) }\end{array}$ & $\begin{array}{r}\text { Injection timing* } \\
\text { (CAD bTDC) }\end{array}$ & $\begin{array}{r}\text { EGR } \\
(\%)\end{array}$ \\
\hline 1 & 2000 & 40 & 40 & 1.0 & 200 & 301 & $0 / 10^{\dagger}$ \\
\hline 2 & 1250 & $20 / 40^{\dagger}$ & 0 & 1.0 & 60 & 329 & 0 \\
\hline 3 & 3000 & 60 & $66 / 115^{\dagger}$ & 1.0 & 200 & 321 & 10 \\
\hline 4 & 4000 & 40 & 100 & $1.0 / 0.875^{\dagger}$ & 200 & 329 & 10 \\
\hline
\end{tabular}




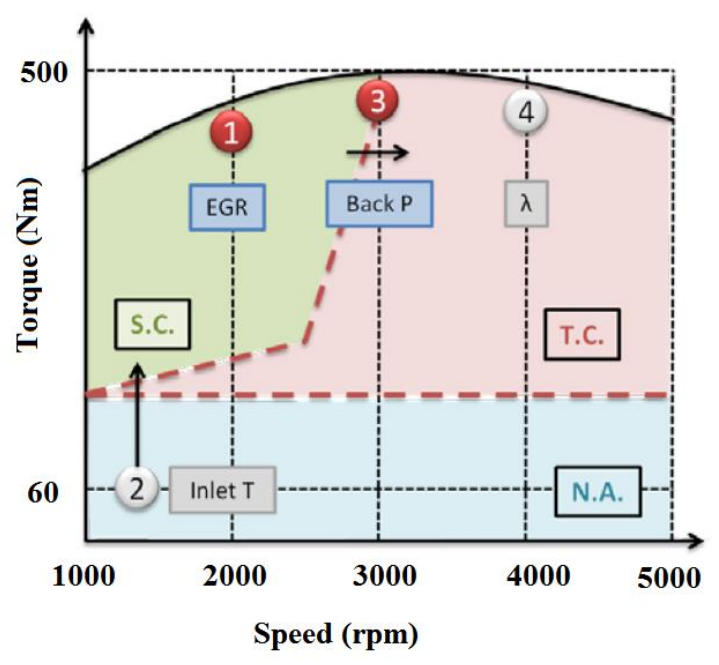

Figure 1: Engine operating points (adapted from [5])

Table 4: Experimental load achieved for each fuel (bar BMEP)

\begin{tabular}{lrrrrr}
\hline Test point & Base & Base rpt & E20 & E85 & GEM \\
\hline $\mathbf{1 ~ ( 0 \% ~ E G R ) ~}$ & 26.26 & 26.34 & 27.75 & 28.60 & 28.05 \\
$\mathbf{1}(\mathbf{1 0} \%$ EGR) & 26.15 & 26.11 & 28.17 & 29.52 & 29.79 \\
$\mathbf{2}$ & 3.76 & 3.77 & 3.77 & 3.77 & 3.77 \\
$\mathbf{3}$ (low EBP) & 23.44 & 23.07 & 24.79 & 25.70 & 25.27 \\
$\mathbf{3}$ (high EBP) & 21.94 & 21.94 & 23.47 & 24.82 & 24.51 \\
$\mathbf{4}(\boldsymbol{\lambda}=\mathbf{1 . 0})$ & 25.44 & 25.48 & 25.55 & 26.24 & 26.43 \\
$\mathbf{4}(\boldsymbol{\lambda}=\mathbf{0 . 8 7 5})$ & 24.66 & 24.57 & 24.99 & 25.82 & 26.42 \\
\hline
\end{tabular}

The test points were run fully warm and in a fixed order, namely that shown in Table 3, with a period of engine stabilization prior to each measurement. DMS data was taken for at least $30 \mathrm{~s}$ logged at $1 \mathrm{~Hz}$ downsampled from $10 \mathrm{~Hz}$. The standard deviations presented on the results correspond to the standard deviation of this $1 \mathrm{~Hz}$ data over the logging period. The full load test points were taken at 10 spark timings, Knock Limited Spark Advance (KLSA) and nine retardations in increments of $1 \mathrm{CAD}$. Test point $2(1250 \mathrm{rpm} / 3.77 \mathrm{bar}$ BMEP) was measured at three injection timings (baseline and \pm 10 CAD) and seven spark timings (at the baseline injection timing). A more complete description of the test matrix is given in [5]. 


\section{Test fuels}

The results from four fuels are presented in this work, all of which were supplied by Shell Global Solutions. The base fuel was an EN228 compliant gasoline representative of UK market fuel (containing up to $5 \% \mathrm{v} / \mathrm{v}$ ethanol); three other oxygenate blends were tested: E20, E85, and GEM (a blend of gasoline, ethanol, and methanol designed to be isostoichiometric with E85) - the GEM blend tested here is approximately the same as "Blend C" tested by Pearson et al. [24] and Turner et al. [26]. All of the blends tested are so-called match blends, which are more commercially representative, as opposed to splash blends, and hence do not have the same base gasoline. The specifications of all of the fuels tested are shown in Table 5 and a more detailed breakdown is shown in Table 6.

\section{Table 5: Test fuel specification}

\begin{tabular}{|c|c|c|c|c|c|c|c|c|c|c|}
\hline Fuel & RON & MON & $\begin{array}{l}\text { RVP } \\
(\mathrm{kPa})\end{array}$ & $\begin{array}{r}\text { Stoichio } \\
\text { metric } \\
\text { AFR }\end{array}$ & $\begin{array}{l}\text { FBP* } \\
\left({ }^{\circ} \mathrm{C}\right)\end{array}$ & $\begin{array}{c}\text { Ethanol } \\
(\% \mathrm{v} / \mathrm{v})\end{array}$ & $\begin{array}{r}\text { Methanol } \\
(\% \mathrm{v} / \mathrm{v})\end{array}$ & $\mathbf{C}$ & $\mathbf{H}$ & $\overline{\mathbf{O}}$ \\
\hline Method & & & $\begin{array}{r}\text { ASTM } \\
5191\end{array}$ & & $\begin{array}{r}\text { ASTM } \\
\text { D86 }\end{array}$ & & & & & \\
\hline Base & 97.0 & 85.3 & 75.0 & 14.1 & 188.4 & 4.91 & 0.00 & 6.05 & 11.11 & 0.10 \\
\hline E20 & 99.6 & 85.7 & 57.8 & 13.3 & 183.6 & 19.49 & 0.16 & 4.98 & 9.68 & 0.34 \\
\hline E85 & 107.4 & 89.5 & 44.4 & 9.63 & 78.4 & 85.20 & 0.71 & 2.31 & 6.36 & 0.93 \\
\hline GEM & 106 & 88.1 & 84.4 & 9.74 & 73.9 & 22.60 & 41.50 & 2.16 & 5.78 & 0.83 \\
\hline
\end{tabular}

*note that the FBP from the ASTM D86 method may differ from the true thermodynamic FBP

Table 6: Detailed test fuel composition

\begin{tabular}{lrrrrrrr}
\hline Fuel & $\begin{array}{r}\text { n-Paraffins } \\
(\% \mathrm{v} / \mathrm{v})\end{array}$ & $\begin{array}{r}\text { Isoparaffins } \\
(\% \mathrm{v} / \mathrm{v})\end{array}$ & $\begin{array}{r}\text { Olefins (including dienes) } \\
(\% \mathrm{v} / \mathrm{v})\end{array}$ & $\begin{array}{r}\text { Naphthenes } \\
(\% \mathrm{v} / \mathrm{v})\end{array}$ & $\begin{array}{r}\text { Aromatics } \\
(\% \mathrm{v} / \mathrm{v})\end{array}$ & $\begin{array}{r}\text { Oxygenates } \\
(\% \mathrm{v} / \mathrm{v})\end{array}$ & $\begin{array}{r}\text { Unknowns } \\
(\% \mathrm{v} / \mathrm{v})\end{array}$ \\
\hline Base & 11.4 & 32.8 & 14.3 & 3.9 & 32.4 & 4.9 & 0.4 \\
$\mathbf{E 2 0}$ & 7.7 & 23.6 & 16.7 & 3.6 & 28.2 & 19.7 & 0.5 \\
$\mathbf{E 8 5}$ & 1.8 & 4.6 & 1.9 & 0.4 & 5.2 & 86.0 & 0.1 \\
GEM & 4.7 & 11.7 & 6.2 & 1.6 & 11.3 & 64.1 & 0.5 \\
\hline
\end{tabular}

\section{Results}

The results reported here were part of a larger set of experiments testing 14 different fuels, which have been reported elsewhere $[5,34,38]$. The oxygenate fuels were three of these 14 
fuels, and the base fuel was tested at the start and end of the experiments reported here for quality control (these have been labelled Base and Base rpt in the results plots). More details of the test procedure are given in the previously reported work $[5,34,38]$. Total particle number emissions are presented as digitally filtered results [5]. It should be noted that the effect of the digital filtering is to give a count efficiency of $50 \%$ at $23 \mathrm{~nm}$ and $90 \%$ at $41 \mathrm{~nm}$, and that this replicates the effect of the PMP protocol, the legislatively compliant methodology for counting particles in Europe [39]. This will result in the nucleation mode peak below $10 \mathrm{~nm}$ not being counted at all. The size distributions presented are unfiltered.

\section{$1250 \mathrm{rpm} / 3.77$ bar BMEP (Test point 2)}

Figure 2 shows the Brake Specific Particle Number (BSPN) emissions at $1250 \mathrm{rpm} / 3.77 \mathrm{bar}$ BMEP, an NEDC minimap point. It should be noted that to present the results clearly the ordinate has a logarithmic scale. The three repeats of the baseline fuel (taken on three different days over a period of weeks) give similar PN emissions, giving confidence in the repeatability of these results. The E20 fuel emits roughly twice as many particles as the baseline at this condition. Both E85 and GEM emit three orders of magnitude fewer particles than the baseline gasoline and approaching the detection limit for the instrument (this is also why the standard deviation of those results increases). At this test point, the engine speed is slow and hence there is a lot of time available for mixture preparation (for the purposes of this work, "good" mixture preparation is a fully evaporated fuel/air mix, and "poor" where the fuel has not fully evaporated and not fully mixed with the air), despite the high $\Delta \boldsymbol{H}_{\boldsymbol{v a p}}$ $(\mathrm{kJ} / \mathrm{kg}$ stoichiometric mixture) of the E85 and GEM fuels. The time available, combined with their low Final Boiling Points (FBP) (see Table 5), means that it seems that they are fully evaporated at the point of ignition, and the bonded oxygen is dominating leading to very complete combustion and contributing to the extremely low levels of particles. 
Given that one of the purposes of this test point is to validate against other naturally aspirated engines, it is pleasing to see that these results agree closely with work in the literature $[13,40$, 41].

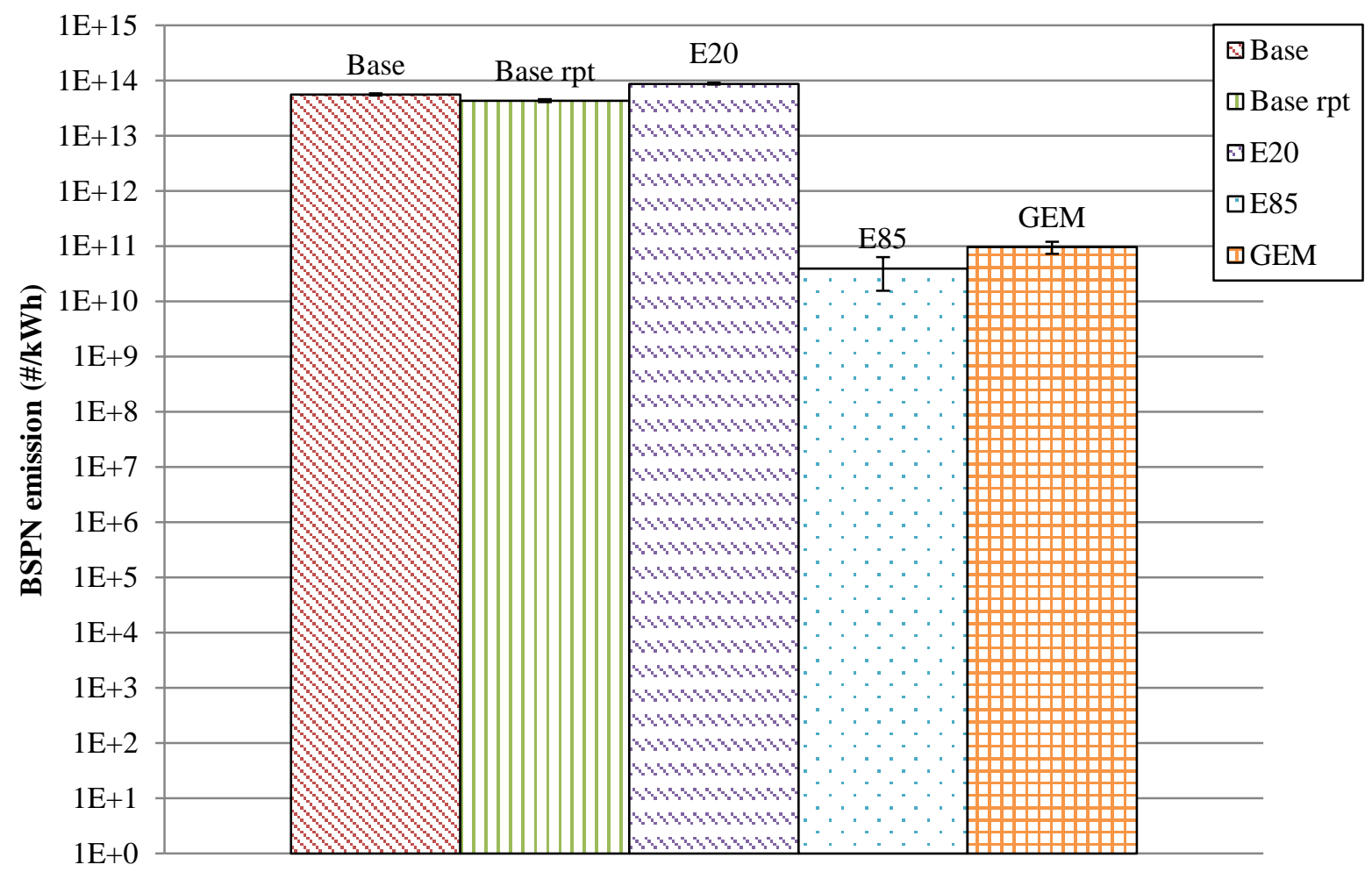

Figure 2: BSPN emissions at $1250 \mathrm{rpm} / 3.77 \mathrm{bar} \mathrm{BMEP}\left(20^{\circ} \mathrm{C}\right.$ inlet air temperature $)$ E85 and GEM can be seen to emit around three orders of magnitude fewer particles than the baseline gasoline. Conversely E20 emits just under double the number of particles compared to the baseline. The error bars correspond to $\pm \sigma$, and note the logarithmic scale on the ordinate

Figure 3 shows the particle size distributions at $1250 \mathrm{rpm} / 3.77$ bar BMEP. Consistent size distributions can be seen between the baseline and E20 fuels, with a peak at around $32 \mathrm{~nm}$ and $150 \mathrm{~nm}$. Given the low overall levels of PN emission with GEM and E85, it is more challenging to measure their size distributions; however, the distribution is still clearly bimodal with peaks at $50 \mathrm{~nm}$ and $200 \mathrm{~nm}$. 


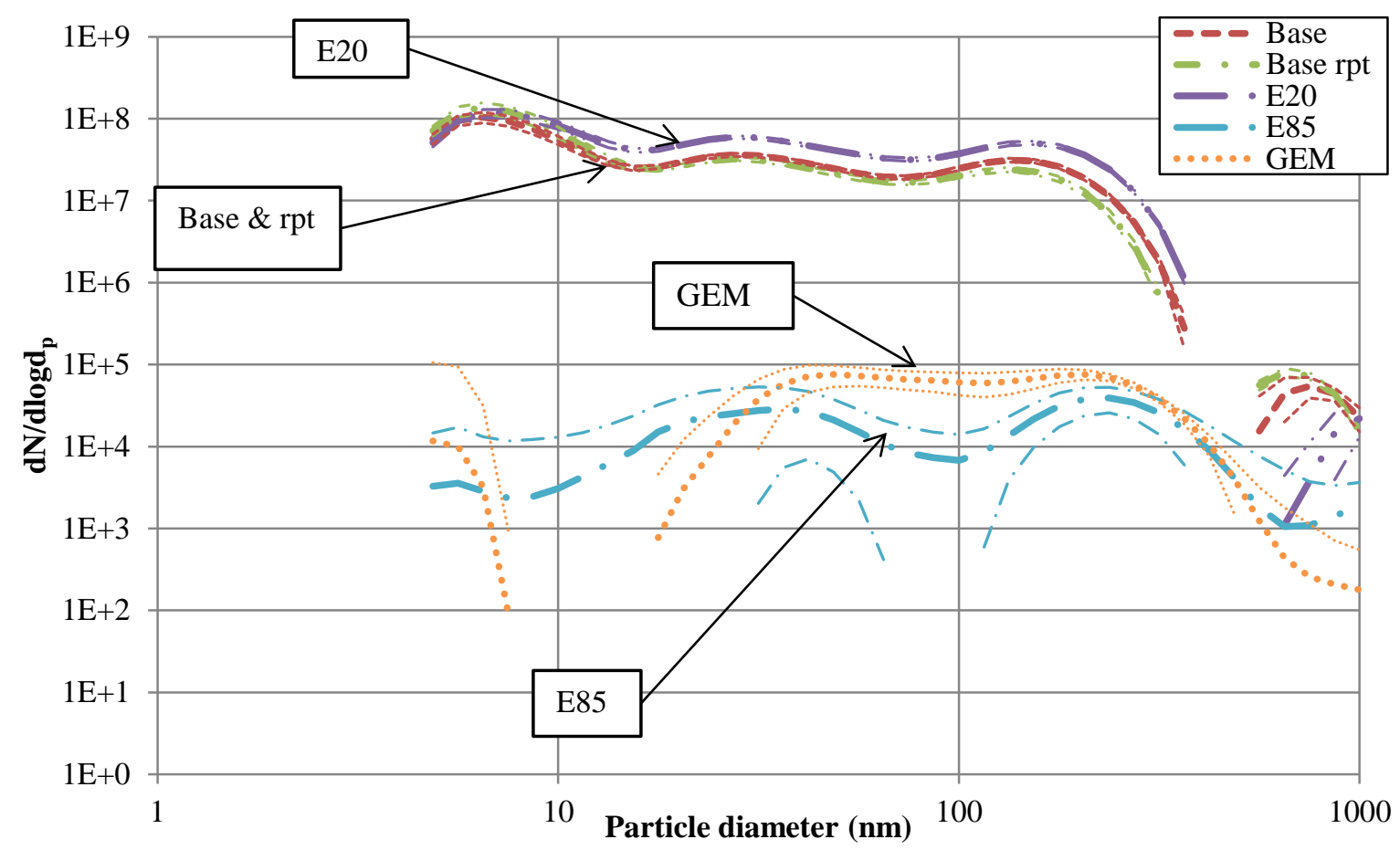

Figure 3: Unfiltered particle size distributions at $1250 \mathrm{rpm} / 3.77 \mathrm{bar} \mathrm{BMEP}\left(20^{\circ} \mathrm{C}\right.$ inlet air temperature). Compared to baseline gasoline and E20 both high alcohol blend fuels give very low levels of particulate emission (note the logarithmic scale). The thin lines correspond to $\pm \sigma$

At this test condition the inlet air temperature was varied from $20^{\circ} \mathrm{C}$ to $40{ }^{\circ} \mathrm{C}$ and a small injection timing sweep was carried out. No significant difference in PN emissions due to oxygenate content of the fuel was noted when either of these were conducted.

\section{0rpm / full load (Test point 1)}

Figure 4 shows the BSPN emission at $2000 \mathrm{rpm} /$ full load. At 0\% EGR the baseline gasoline gives the lowest emissions, with E85, then E20, then GEM increasing emissions. In contrast with the $1250 \mathrm{rpm} / 3.77$ bar BMEP GEM now gives the highest rather than the lowest PN emission, and E85 emits more than gasoline. Clearly with less time to evaporate at the higher engine speed, the high $\Delta \boldsymbol{H}_{\boldsymbol{v} \boldsymbol{a p}}(\mathrm{kJ} / \mathrm{kg}$ stoichiometric mixture) of both of these fuels is having an effect, resulting in poorer mixture formation and hence higher PN emissions. 
At $10 \%$ EGR the fuels behave somewhat differently, most fuels have a modest increase in PN, in line with previously reported results [5]. The inlet manifold pressure is higher with EGR (an increase of $0.2 \mathrm{bar}$ ), which will lead to an increase in cylinder pressure at injection, which in turn results in the fuel penetrating less far into the cylinder before evaporation, resulting in a less homogeneous mixture, and hence higher PN emissions. E85 on the other hand shows a decrease in PN with EGR [42]. In addition, running the engine on E85 leads to the lowest exhaust temperature of all of the fuels tested (around $50{ }^{\circ} \mathrm{C}$ lower than the base fuel) which suggests reduced post-flame oxidation.

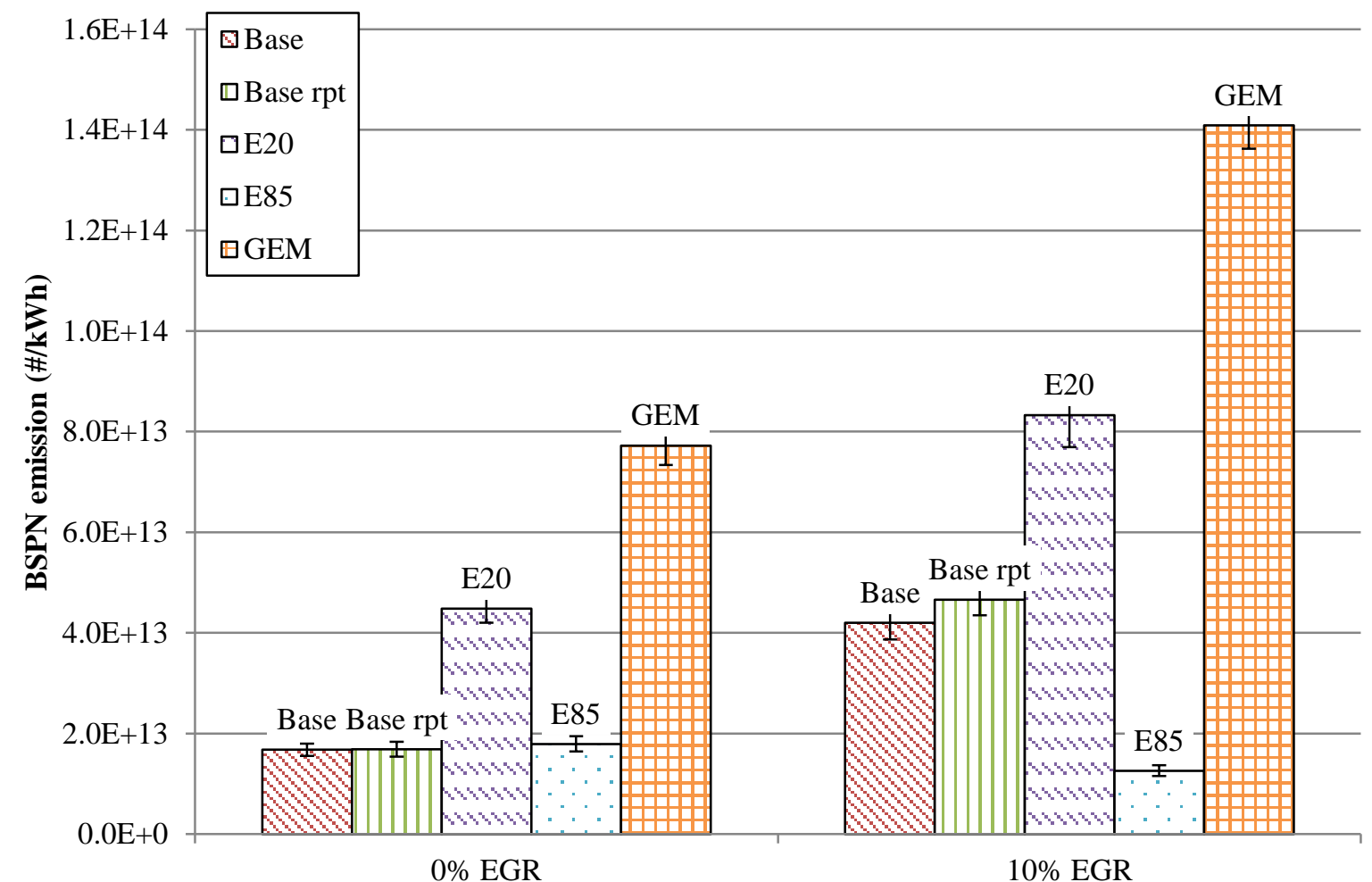

Figure 4: BSPN emissions at $2000 \mathrm{rpm} /$ full load and varying EGR rate. The effect of adding EGR is to increase the number of particles emitted for most fuels, however with E85 adding EGR reduces the PN emission. The error bars correspond to $\pm \sigma$

Figure 5 shows the unfiltered particle size distributions at $2000 \mathrm{rpm} /$ full load (10\% EGR). Again the nucleation mode peak would be discounted in a legislatively compliant test, and an accumulation mode peak can be seen at around $35 \mathrm{~nm}$ for all fuels. In addition the GEM fuel 
peak extends to around $65 \mathrm{~nm}$ showing that not only is GEM producing more particulates, but they are also larger - and hence would contribute more to the particle mass emission from GEM.

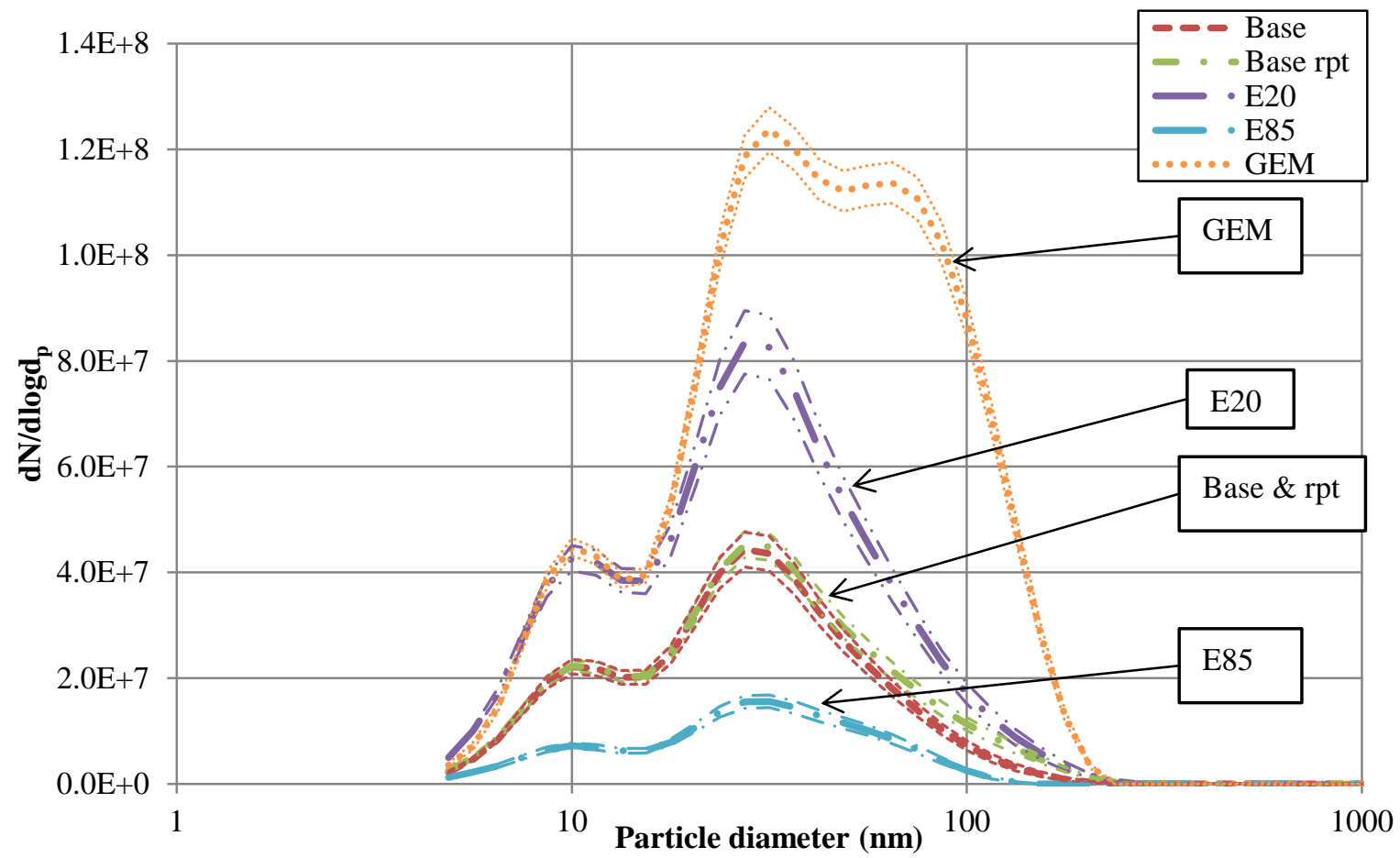

Figure 5: Unfiltered particle size distributions at $2000 \mathrm{rpm} /$ full load (10\% EGR). All fuels except GEM can be seen to have an accumulation mode peak at around $35 \mathrm{~nm}$, and GEM produces larger particles - an accumulation mode peak is observed at around $65 \mathrm{~nm}$. The thin lines correspond to $\pm \sigma$

\section{$3000 \mathrm{rpm} /$ full load (Test point 3)}

Figure 6 shows the BSPN emissions at $3000 \mathrm{rpm} /$ full load. This point was run with two exhaust back pressures, simulating a transition between supercharged and turbocharged operation in a compound-charged engine [35]. At low back pressure the trends seen at $2000 \mathrm{rpm} /$ full load hold, with GEM giving the highest emission and the baseline the lowest. As the Exhaust Back Pressure (EBP) is increased, this has the effect of increasing the incylinder residuals, in effect increasing internal EGR, and again similar trends to those seen at $10 \%$ EGR can be seen, albeit at a lower magnitude (as the increase in internal EGR would be less than $10 \%$ ). Although this increase in residuals will lead to an increase in pressure at fuel 
injection (where one might expect higher PN emissions) it is likely that the effect of residuals is to increase the cylinder temperature at injection, promoting spray evaporation and leading to a more homogeneous mixture formation and hence lower PN emissions.

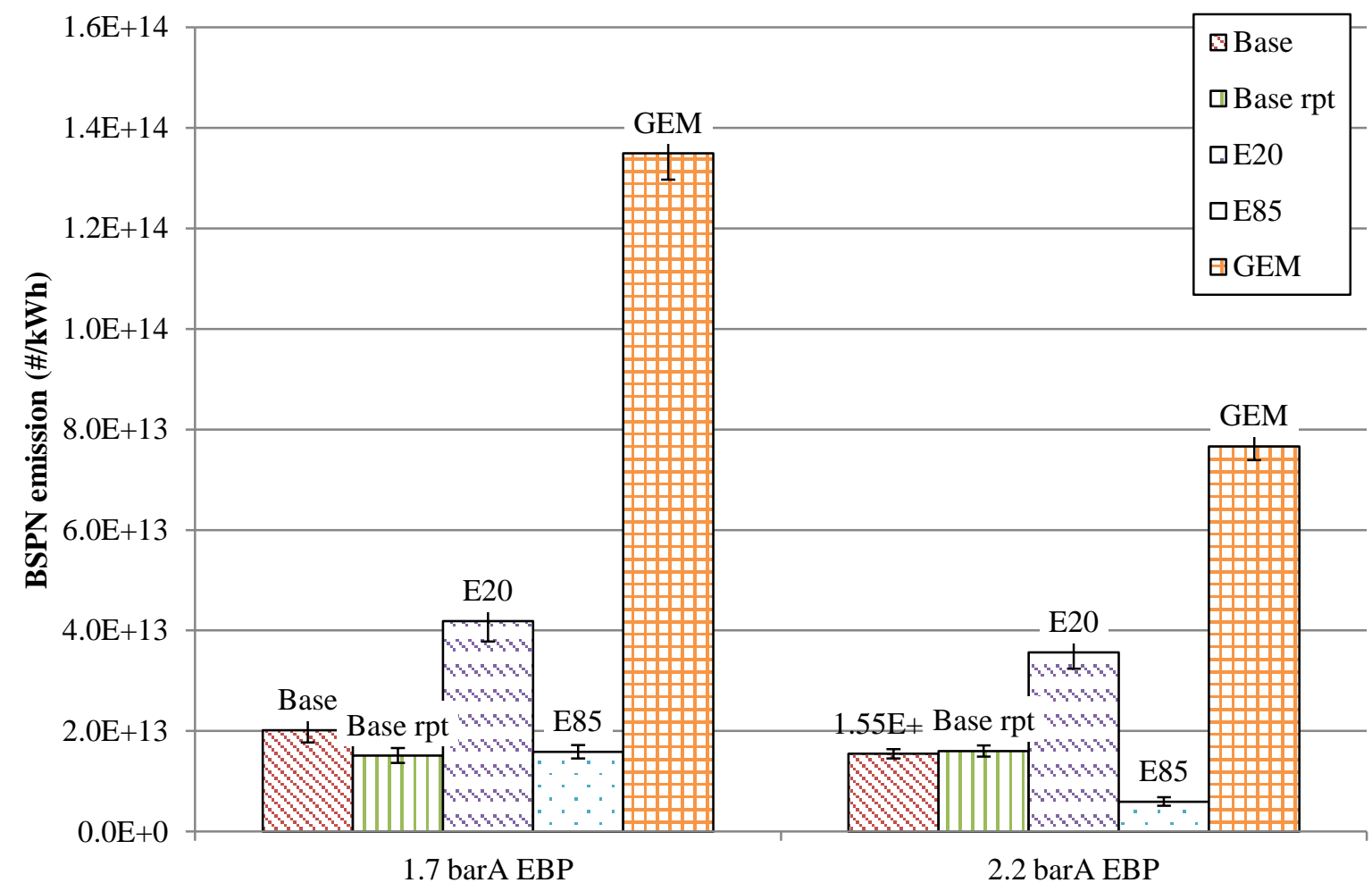

Figure 6: BSPN emissions at 3000rpm / full load and varying exhaust back pressure. GEM emits the highest level of particles at both exhaust back pressures, E20 and the baseline fuel are relatively insensitive to EBP, but E85 and GEM are both reduced by increasing $E B P$. The error bars correspond to $\pm \sigma$

Figure 7 shows the unfiltered particle size distributions at $3000 \mathrm{rpm} /$ full load (2.2 barA EBP). Again, similar to what can be seen at $2000 \mathrm{rpm} /$ full load, there is an accumulation mode peak at around $30 \mathrm{~nm}$, extending up to $50 \mathrm{~nm}$ for the GEM fuel. 


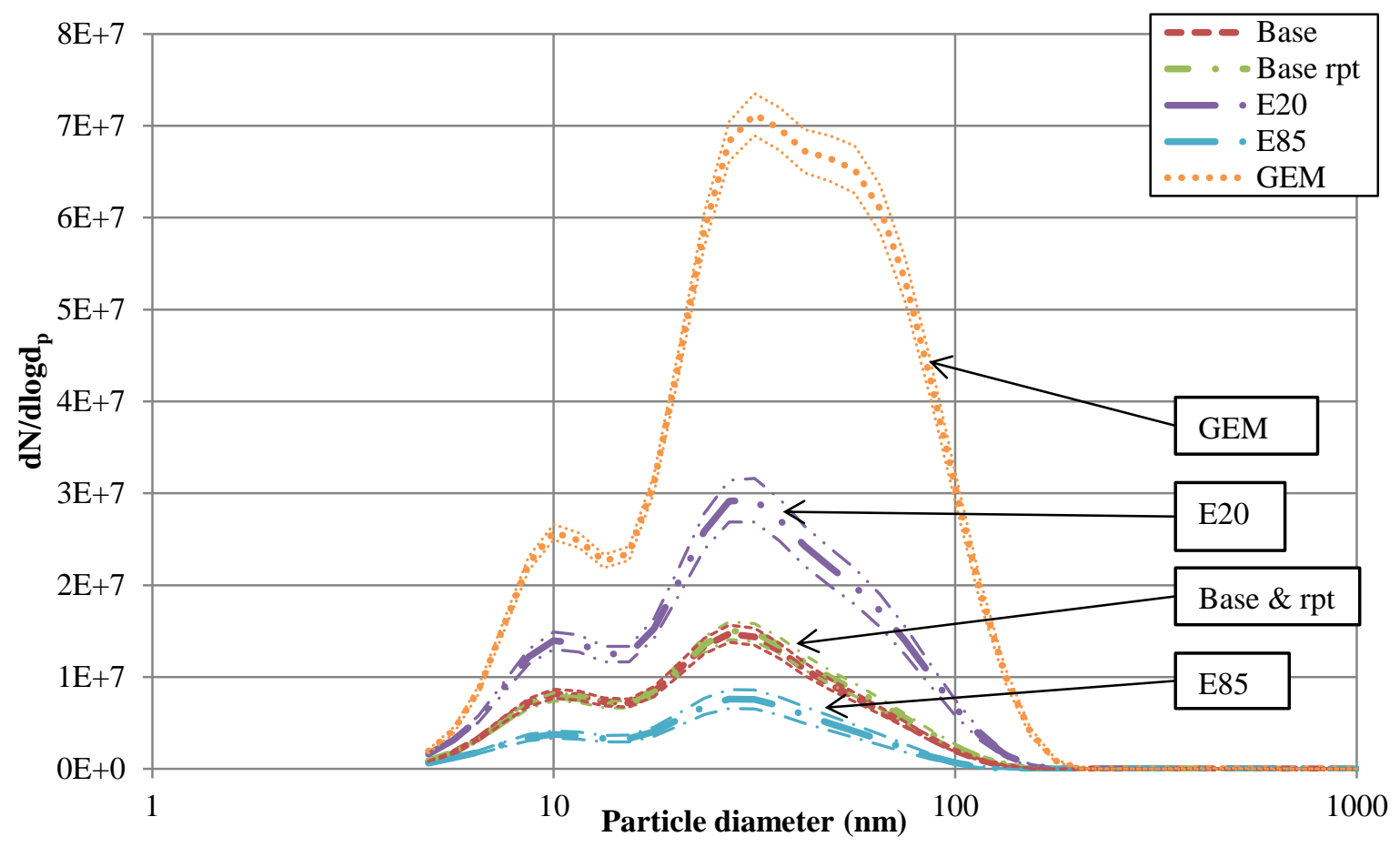

Figure 7: Unfiltered particle size distributions at $3000 \mathrm{rpm} /$ full load (2.2 barA EBP). All fuels except GEM can be seen to have an accumulation mode peak at around $30 \mathrm{~nm}$, and GEM produces larger particles - an accumulation mode peak is observed at around $57 \mathrm{~nm}$. The thin lines correspond to $\pm \sigma$

\section{0rpm / full load (Test point 4)}

Figure 8 shows the BSPN emissions at $4000 \mathrm{rpm} /$ full load. At this high speed, highly boosted point similar trends to those at the other full load points are visible, however the proportional increase of the GEM fuel is lower, and the E85 gives exceptionally low PN emissions despite the very high load (25-26 bar BMEP depending on the fuel - see Table 4). With these high boost levels and slightly lower levels of fuel injection (due to lower load at $4000 \mathrm{rpm}$ compared to the lower speeds which can reach up to 30 bar BMEP) compared to the $2000 \mathrm{rpm}$ and $3000 \mathrm{rpm}$ cases it seems that the effect of the high $\Delta \boldsymbol{H}_{\boldsymbol{v a p}}(\mathrm{kJ} / \mathrm{kg}$ stoichiometric mixture) is lessened and the mixture is slightly better prepared compared to these lower speed cases. In addition, the higher engine speed will be causing higher charge motion in-cylinder, which again will lead to better air-fuel mixing and again better mixture preparation. 
As the mixture is enriched to $\lambda=0.875$ the baseline and E20 cases increase the levels of PN emitted significantly, as would be expected, however the increase in E85 and GEM fuels is, while still present, far less significant - E85 emits only a quarter of the particles of the baseline gasoline at $\lambda=0.875$. This agrees with the trends noted in the literature [20] and given the importance on rich mixture excursions on PN emissions [37] and forthcoming "real world" emissions testing, this is an important result.

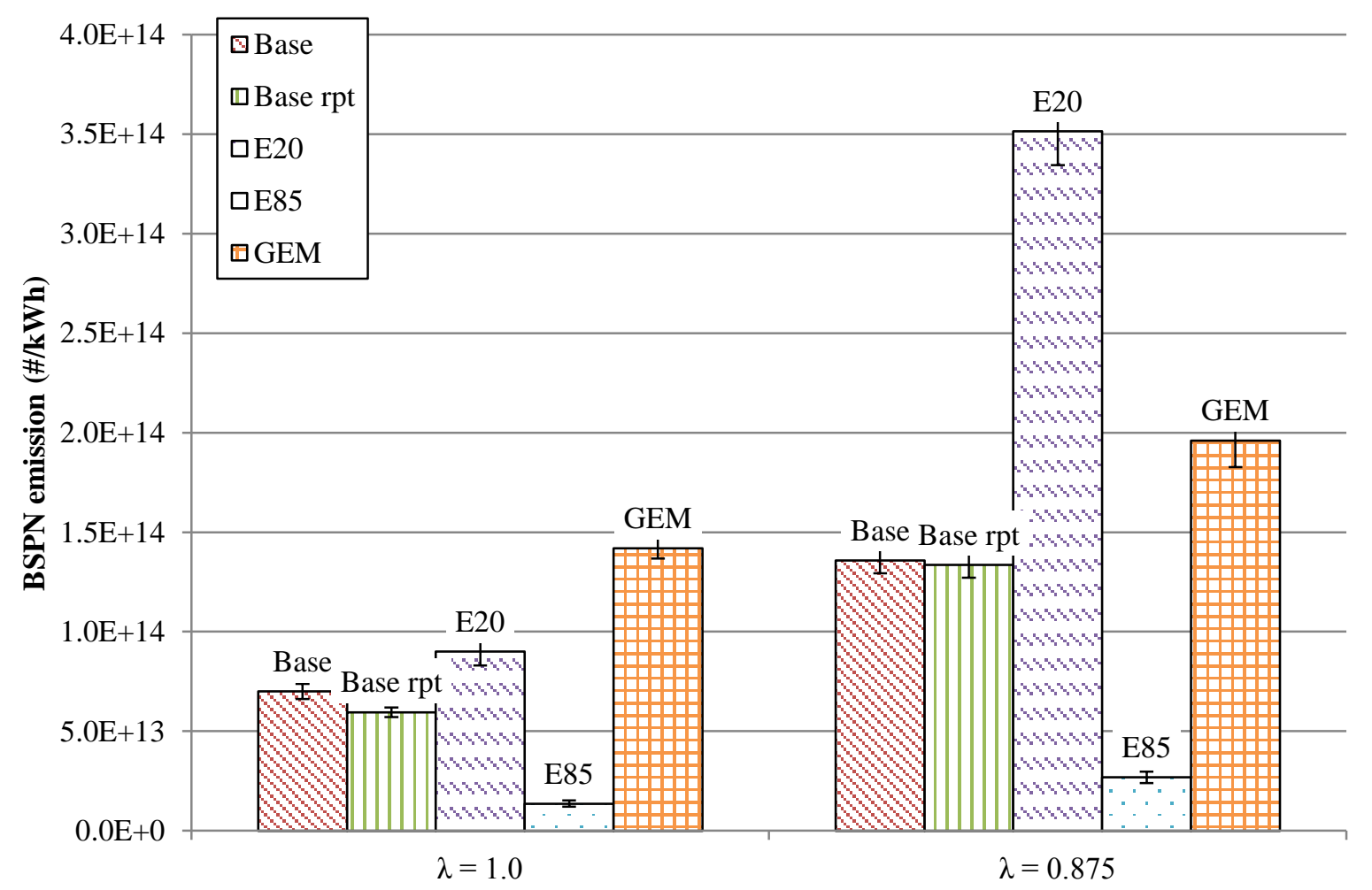

Figure 8: BSPN emissions at $4000 \mathrm{rpm} /$ full load with varying relative air-fuel ratio. Enriching the mixture can be seen to increase the PN emissions significantly for most fuels, however E85 and GEM only show a minor increase (although the overall emissions from GEM remain high). The error bars correspond to $\pm \sigma$

Figure 9 shows the unfiltered particle size distributions at $4000 \mathrm{rpm} /$ full load $(\lambda=1.0)$. Here there is a clear accumulation mode peak at $30 \mathrm{~nm}$ for all fuels, which although the overall size and shape of the distributions change, the peak location appears to remain the same, independent of which fuel is being tested. 


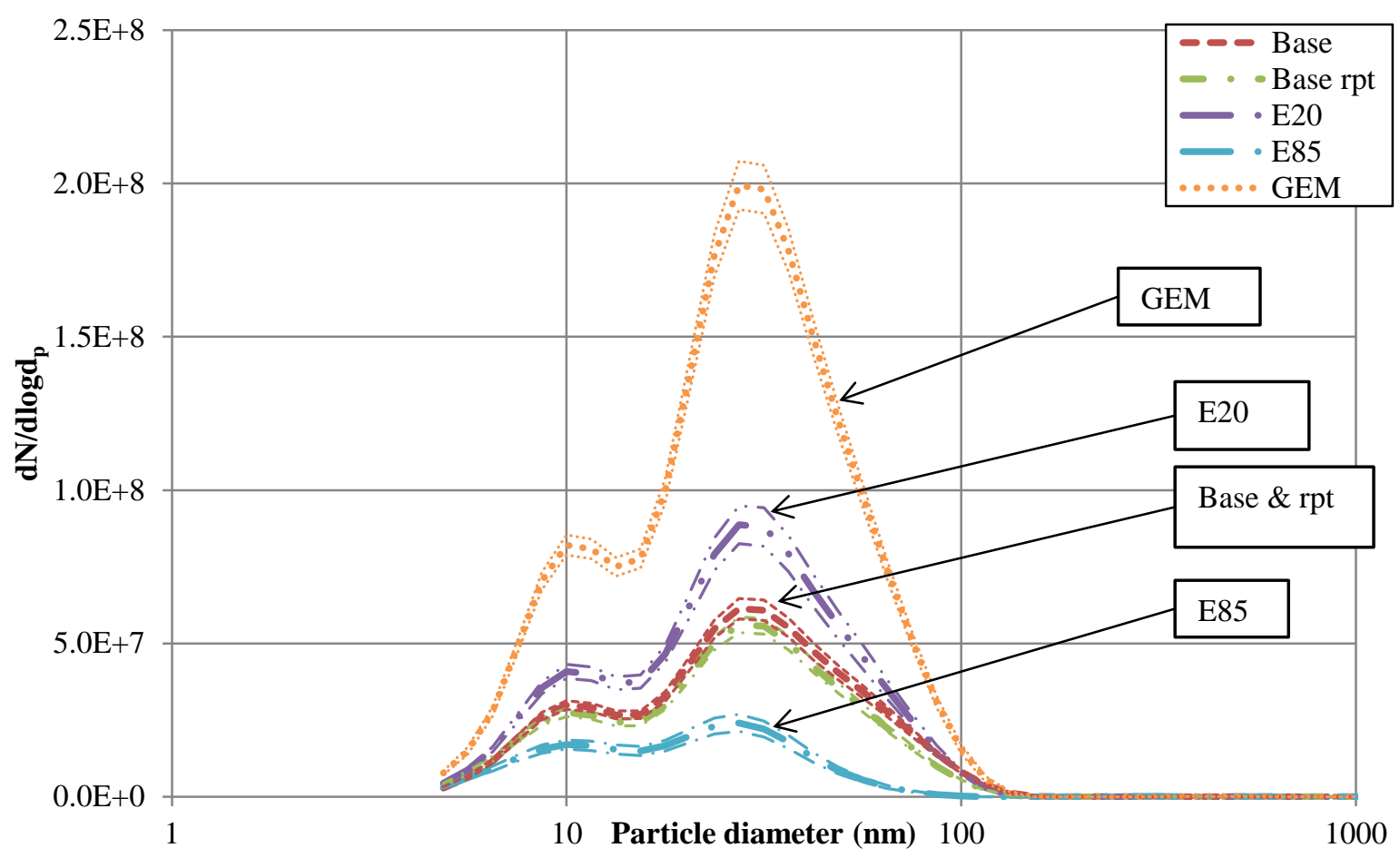

Figure 9: Unfiltered particle size distributions at $4000 \mathrm{rpm} /$ full load $(\lambda=1.0)$. All fuels have an accumulation mode peak at around $30 \mathrm{~nm}$, with no variation in particle size with fuel composition. The thin lines correspond to $\pm \sigma$

\section{Effect of ignition timing on PN emissions}

At all test conditions an ignition timing sweep was conducted (from KLSA). While this changed the overall magnitudes of PN emissions, as might be expected, these changes were not influenced by the fuel composition in any significant way; a representative result is shown as Figure 10. Previous work [5] has looked at the impact of ignition timing on PN from this engine, and the results here to not deviate from those conclusions. 


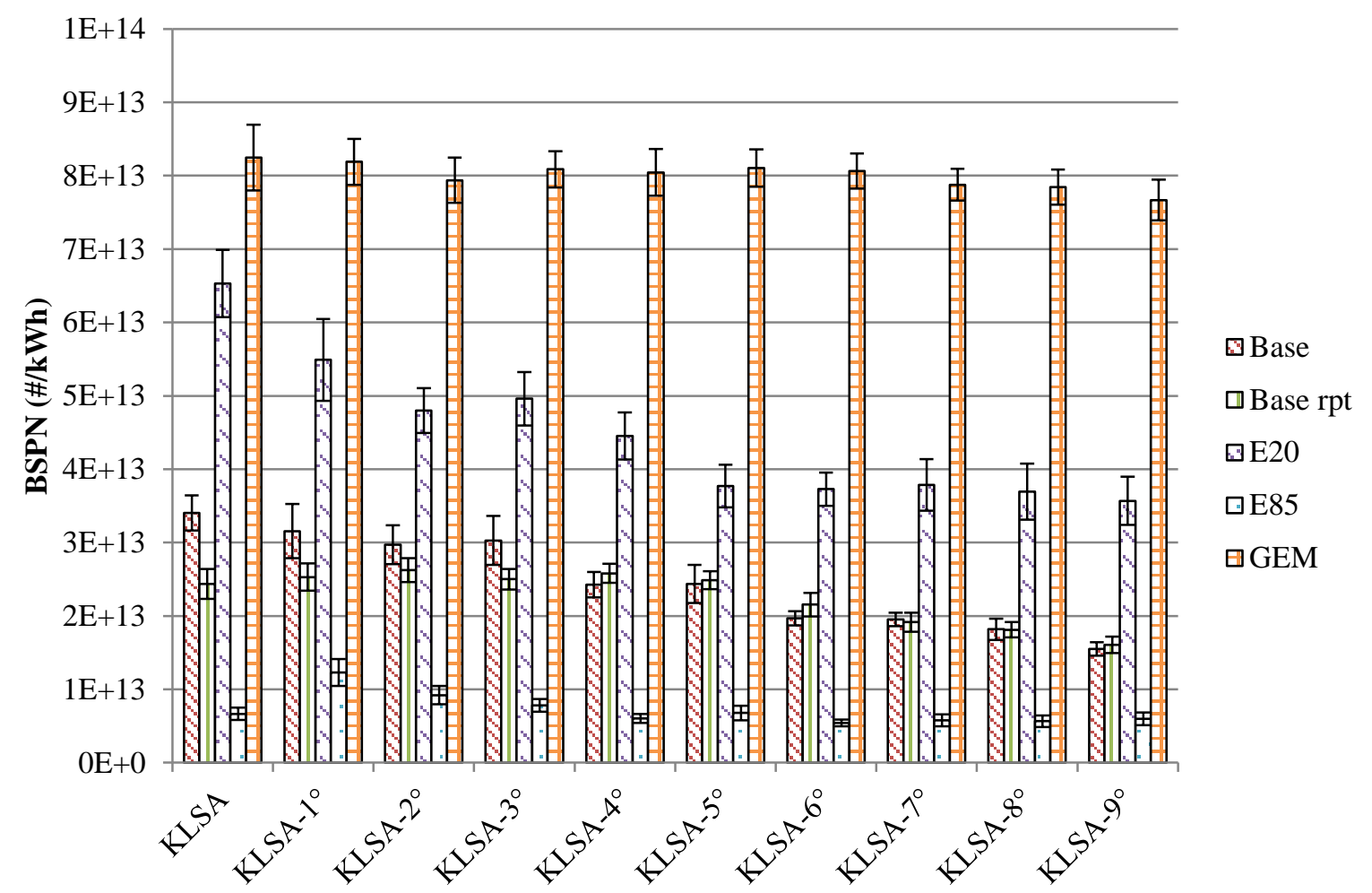

Figure 10: BSPN emissions at 3000rpm / full load as the ignition timing is retarded from KLSA. All fuels show reductions in BSPN as the ignition timing is retarded. The error bars correspond to $\pm \sigma$

\section{Discussion and conclusions}

The PN emissions from a baseline gasoline and three different oxygenate fuel match blends have been measured from a highly boosted engine operating at up to 30 bar BMEP.

E20

E20 appears to share many characteristics with the base fuel; however the two fuels do not share a common gasoline. Here, the E20 (ethanol having a higher latent heat than gasoline) will take longer to evaporate, and induce more local cooling, meaning that the mixture is less well prepared, resulting in higher PN emissions for E20 when compared with the base fuel. This is true at all operating conditions. No notable difference in the size of the particles emitted was seen with E20 relative to the base fuel. 


\section{E85}

The PN emissions from E85 are very low throughout all of the test points. Ethanol is known to have a low sooting tendency [22] which will promote low levels of PN from engines. In addition Sakai and Rothamer in their recent work [21] showed that the chemical properties of ethanol, in particular chemically bonded oxygen, are a significant factor in reducing PN emissions. E85 also has a low FBP $\left(78.4^{\circ} \mathrm{C}\right.$ by the ASTM D86 method) which will promote good evaporation, and hence mixture preparation. In addition, this exceptionally low FBP arises as a result of ethanol forming an azeotrope with aromatic components at around the FBP, resulting in their evaporation at a temperature below that which would be expected (its FBP is lower than the boiling point of any aromatic component despite Table 6 showing that the fuel contains $5 \% \mathrm{v} / \mathrm{v}$ aromatics). For example ethanol (boiling point: $78.2^{\circ} \mathrm{C}$ ) and toluene (boiling point: $111^{\circ} \mathrm{C}$ ), a common aromatic, form a minimum-boiling azeotrope at $68 \%(\mathrm{~m} / \mathrm{m})$ ethanol at a temperature of $76.9^{\circ} \mathrm{C}$ [9]. The presence of this azeotrope influencing evaporative behaviour means that the aromatic components in the fuel will be burning in a mixture with ethanol, which is oxygen rich, perhaps negating their known particulate forming effects [43]. Of course the high level of oxygenates overall will mean that there is a dilution of all of the other components which might otherwise lead to high PN emissions [44], further reinforcing the results presented in this paper.

\section{GEM}

The notable difference between the PN emissions from E85 and GEM (which has the same stoichiometric AFR as E85) is of interest if GEM is to be a drop-in replacement fuel for E85, because the effect of this change on PN emissions is marked.

The GEM fuel shows very high (highest of the fuels tested) particulate emissions in Test Conditions 1, 3, and 4, but among the lowest at Test Condition 2 (the NEDC minimap point). It is notable that the high PN emissions are occurring at the high speed, high load conditions, 
but not at the low speed, low load condition. Given the presence of methanol in the fuel, this gives the fuel a high vapour pressure $(84.4 \mathrm{kPa})$ and $\Delta \boldsymbol{H}_{\boldsymbol{v a p}}(\mathrm{kJ} / \mathrm{kg}$ stoichiometric mixture). It is likely that the time available at the high speed conditions, alongside the local cooling caused by the methanol beginning to evaporate on injection (due to its high vapour pressure and $\Delta \boldsymbol{H}_{\boldsymbol{v a p}}$ ) is leading to very poor mixture formation. This will lead to high PN emissions at high engine speeds. The GEM fuel gave a large average accumulation mode particle diameter at the $2000 \mathrm{rpm}$ and $3000 \mathrm{rpm}$ test conditions compared to all of the other fuels, and this would also be expected to increase disproportionately the particle mass emission from the GEM fuel.

Figure 11 shows PN emissions from fuels containing different percentages of ethanol and methanol in a single cylinder engine at light load (2.8 bar IMEP, injection at 280 CAD bTDC and ignition at $35 \mathrm{CAD}$ bTDC) from previous work by Leach et al. [13]. It can be seen that initially, adding oxygenates increases the PN emissions, before decreasing again. At low levels of oxygenates, this trend follows the increasing $\Delta \boldsymbol{H}_{\text {vap }}(\mathrm{kJ} / \mathrm{kg}$ stoichiometric mixture) of the fuels suggesting that the extra energy required to evaporate the mixture is leading to poorer mixture preparation. At higher oxygenate content, the effects of having chemically bonded oxygen present seem to dominate, causing a reduction in $\mathrm{PN}$; this reflects what is seen in the literature [45]. The trends in Figure 11 follow that of the vapour pressure curves of respective fuel/alcohols mixtures, namely, an increase above baseline fuels peaking at around $45 \%$ alcohol content before decreasing with further increase in alcohol. 


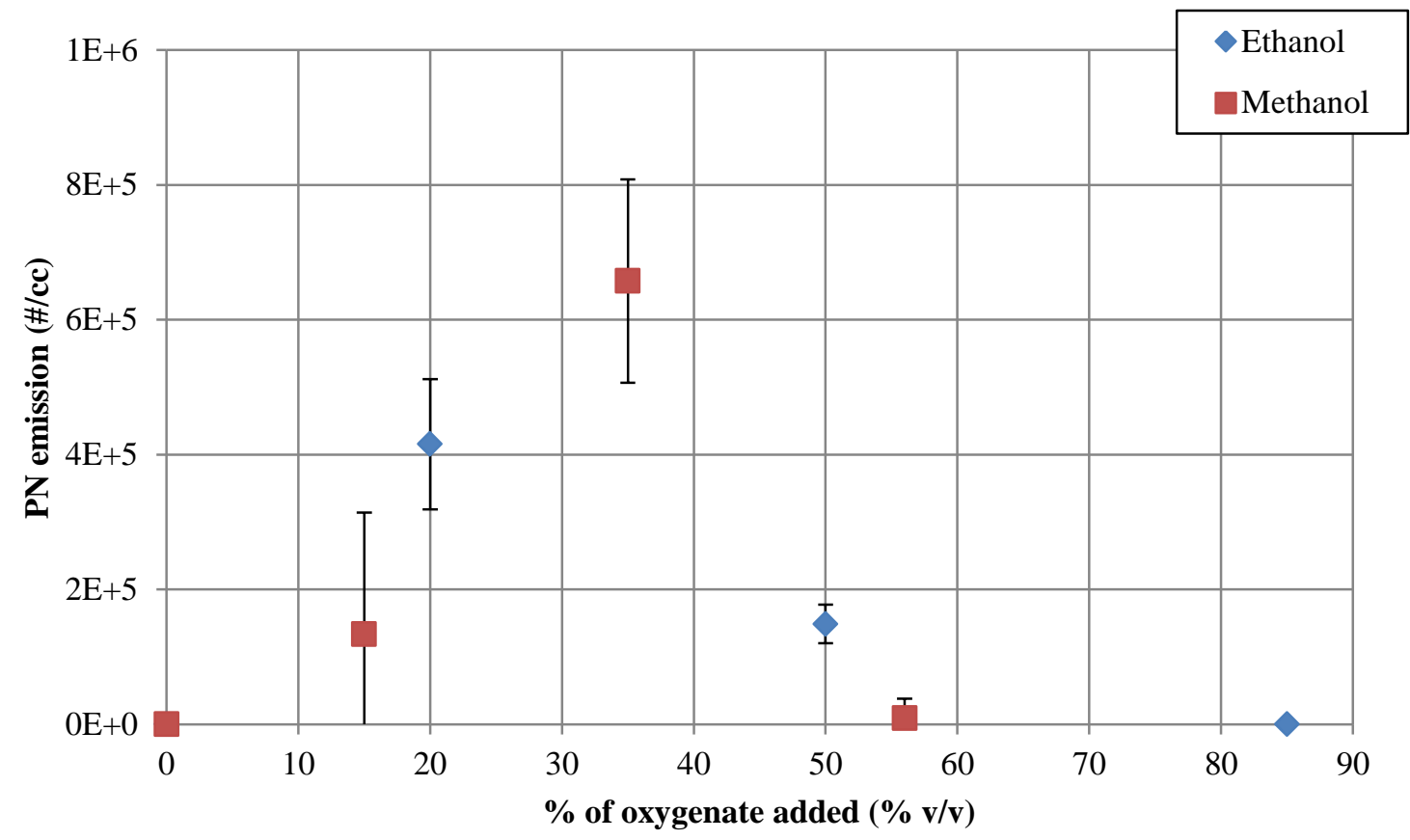

Figure 11: PN emissions from ethanol and methanol gasoline blends with a simple four component model gasoline [13] at light load from a single cylinder engine. The trends here agree with the results obtained at high load on the UB100 engine. The error bars correspond to $\pm \sigma$. (Data from [13])

Looking at the results in Figure 11, it can be seen that the results obtained at light load in a single cylinder engine match the results obtained from this engine. E85 gives very low levels of PN throughout all test points, and E20 gives higher levels of PN than the base gasoline throughout. This implies that the two effects suggested above also hold in a highly boosted engine. The GEM fuel (with $64 \%$ oxygenates), does not quite follow the trend shown in Figure 11 at high load (although it does at low load), perhaps suggesting that there is an influence of base gasoline, which is constant in Figure 11, but not in this work, although this may just be an engine-specific effect.

These are important considerations for GEM's potential as a "drop-in" replacement for E85. Overall further investigation would be justified, including blends of other alcohols and oxygenates configured in this iso-stoichiometric manner. 


\section{Acknowledgments}

The authors acknowledge the Technology Strategy Board (now Innovate UK), the UK's innovation agency, for the partial funding of this work. Consortium members GE Precision Engineering, Lotus Engineering, CD-Adapco, Imperial College London, and the University of Leeds have all made various portions of this work possible.

\section{Funding}

This work was funded by Jaguar Land Rover, Shell, the Technology Strategy Board, and all of the project partners listed above also made contributions. Felix Leach acknowledges the support of an EPSRC studentship.

\section{References}

1. Zhao H. Overview of Gasoline Direct Injection Engines. Advanced direct injection combustion engine technologies and development: Gasoline and gas engines: Woodhead Publishing Ltd; 2010.

2. Friedfeldt R, Zenner T, Ernst R, Fraser A. Three-Cylinder Gasoline Engine with Direct Injection. Auto Tech Review. 2013;2:32-7.

3. $\quad$ Eastwood P. Particulate Emissions from Vehicles: SAE International and John Wiley \& Sons, Ltd.; 2008.

4. Stone CR. Introduction to Internal Combustion Engines. 4th ed: palgrave macmillan; 2012.

5. Leach F, Stone R, Richardson D, Lewis A, Akehurst S, Turner J, Remmert S, Campbell S, Cracknell R. Particulate emissions from a highly boosted GDI engine. International Journal of Engine Research 19(3):347$359,2018$.

6. $\quad$ EN228:2008 Automotive fuels. Unleaded petrol. Requirements and test methods. 2008.

7. $\quad 42$ U.S.C. $\$ 7546$.

8. CONCAWE. Gasoline volatility and vehicle performance. 2012.

9. Zhu Z, Wang L, Ma Y, Wang W, Wang Y. Separating an azeotropic mixture of toluene and ethanol via heat integration pressure swing distillation. Computers \& Chemical Engineering. 2015;76:137-49.

10. Chen L, Stone R, Richardson D. A study of mixture preparation and PM emissions using a direct injection engine fuelled with stoichiometric gasoline/ethanol blends. Fuel. 2012;96:120-30.

11. Bielaczyc, P., Szczotka, A., and Woodburn, J., "The Impact of Fuel Ethanol Content on Particulate Emissions from Light-Duty Vehicles Featuring Spark Ignition Engines," SAE Int. J. Fuels Lubr. 7(1):224-235, 2014, https://doi.org/10.4271/2014-01-1463.

12. Catapano, F., Di Iorio, S., Sementa, P., and Vaglieco, B., "Characterization of Ethanol-Gasoline Blends Combustion processes and Particle Emissions in a GDI/PFI Small Engine," SAE Technical Paper 2014-011382, 2014, https://doi.org/10.4271/2014-01-1382.

13. Leach, F, Stone, R, Davy, M et al. Comparing the effect of different oxygenate components on PN emissions from GDI engines. Internal Combustion Engines Conference (pp. 301-310), Institution of Mechanical Engineers, 2015. (https://ora.ox.ac.uk/objects/uuid:a33ce7aa-d609-462c-94a3-af8e84f7b3e5)

14. Turner J, Lewis A, Akehurst S, Brace C, Verhelst S, Vancoillie J, Sileghem L, Leach F, Edwards P. Alcohol fuels for spark-ignition engines: performance, efficiency and emissions effects at mid to high blend rates for binary mixtures and pure component. Proceedings of the Institution of Mechanical Engineers, Part D: Journal of Automobile Engineering. 2017. 
15. Henkel, S., Hardalupas, Y., Taylor, A., Conifer, C. et al., "Injector Fouling and Its Impact on Engine Emissions and Spray Characteristics in Gasoline Direct Injection Engines," SAE Int. J. Fuels Lubr. 10(2):287295, 2017, https://doi.org/10.4271/2017-01-0808.

16. Davis S, Diegel S, Boundy R. Transportation energy data book: Oak Ridge National Laboratory; 2013.

17. Balabin RM, Syunyaev RZ, Karpov SA. Molar enthalpy of vaporization of ethanol-gasoline mixtures and their colloid state. Fuel. 2007;86:323-7.

18. Linstrom PJ, Mallard W. NIST Chemistry webbook; NIST standard reference database No. 69. 2001.

19. Peckham, M., Finch, A., Campbell, B., Price, P. et al., "Study of Particle Number Emissions from a Turbocharged Gasoline Direct Injection (GDI) Engine Including Data from a Fast-Response Particle Size Spectrometer," SAE Technical Paper 2011-01-1224, 2011, https://doi.org/10.4271/2011-01-1224.

20. Chen, L., Braisher, M., Crossley, A., Stone, R. et al., "The Influence of Ethanol Blends on Particulate Matter Emissions from Gasoline Direct Injection Engines," SAE Technical Paper 2010-01-0793, 2010, https://doi.org/10.4271/2010-01-0793.

21. Sakai S, Rothamer D. Effect of ethanol blending on particulate formation from premixed combustion in spark-ignition engines. Fuel. 2017;196:154-68.

22. Lemaire R, Therssen E, Desgroux P. Effect of ethanol addition in gasoline and gasoline-surrogate on soot formation in turbulent spray flames. Fuel. 2010;89:3952-9.

23. Turner, J., Pearson, R., Purvis, R., Dekker, E. et al., "GEM Ternary Blends: Removing the Biomass Limit by using Iso-Stoichiometric Mixtures of Gasoline, Ethanol and Methanol," SAE Technical Paper 201124-0113, 2011, https://doi.org/10.4271/2011-24-0113.

24. Pearson R, Turner J, Bell A, de Goede S, Woolard C, Davy M. Iso-Stoichiometric Fuel Blends: Characterization of Physico-Chemical Properties for Mixtures of Gasoline, Ethanol, Methanol, and Water Proceedings of the Institution of Mechanical Engineers Part D: Journal of Automobile Engineering. 2014;229:111-39.

25. Sileghem L, Coppens A, Casier B, Vancoillie J, Verhelst S. Performance and emissions of isostoichiometric ternary GEM blends on a production SI engine. Fuel. 2014;117, Part A:286-93.

26. Turner JWG, Pearson RJ, Dekker E, Iosefa B, Johansson K, ac Bergström K. Extending the role of alcohols as transport fuels using iso-stoichiometric ternary blends of gasoline, ethanol and methanol. Applied Energy. 2013;102:72-86.

27. Olah GA, Goeppert A, Prakash GS. Beyond oil and gas: the methanol economy: John Wiley \& Sons; 2011.

28. Kothandaraman J, Goeppert A, Czaun M, Olah GA, Prakash GKS. Conversion of $\mathrm{CO}_{2}$ from Air into Methanol Using a Polyamine and a Homogeneous Ruthenium Catalyst. Journal of the American Chemical Society. 2016;138:778-81.

29. Abu-Isa, I., "Effects of Mixtures of Gasoline With Methanol and With Ethanol on Automotive Elastomers," SAE Technical Paper 800786, 1980, https://doi.org/10.4271/800786.

30. Liu S, Cuty Clemente ER, Hu T, Wei Y. Study of spark ignition engine fueled with methanol/gasoline fuel blends. Applied Thermal Engineering. 2007;27:1904-10.

31. Yanju W, Shenghua L, Hongsong L, Rui Y, Jie L, Ying W. Effects of Methanol/Gasoline Blends on a Spark Ignition Engine Performance and Emissions. Energy \& Fuels. 2008;22:1254-9.

32. Yang C-J, Jackson RB. China's growing methanol economy and its implications for energy and the environment. Energy Policy. 2012;41:878-84.

33. Inal F, Senkan SM. Effects of oxygenate additives on polycyclic aromatic hydrocarbons(pahs) and soot formation. Combustion Science and Technology. 2002;174:1-19.

34. Remmert, S., Cracknell, R., Head, R., Schuetze, A. et al., "Octane Response in a Downsized, Highly Boosted Direct Injection Spark Ignition Engine," SAE Int. J. Fuels Lubr. 7(1):131-143, 2014, https://doi.org/10.4271/2014-01-1397.

35. Turner, J., Popplewell, A., Patel, R., Johnson, T. et al., "Ultra Boost for Economy: Extending the Limits of Extreme Engine Downsizing," SAE Int. J. Engines7(1):387-417, 2014, https://doi.org/10.4271/201401-1185.

36. Reavell, K., Hands, T., and Collings, N., "A Fast Response Particulate Spectrometer for Combustion Aerosols," SAE Technical Paper 2002-01-2714, 2002, https://doi.org/10.4271/2002-01-2714.

37. Braisher, M., Stone, R., and Price, P., "Particle Number Emissions from a Range of European Vehicles," SAE Technical Paper 2010-01-0786, 2010, https://doi.org/10.4271/2010-01-0786.

38. Remmert, S., Campbell, S., Cracknell, R., Schuetze, A. et al., "Octane Appetite: The Relevance of a Lower Limit to the MON Specification in a Downsized, Highly Boosted DISI Engine," SAE Int. J. Fuels Lubr. 7(3):743-755, 2014, https://doi.org/10.4271/2014-01-2718.

39. Andersson J, Giechaskiel B, Muñoz-Bueno R, Sandbach E, Dilara P. Particle Measurement Programme (PMP) Light-duty Inter-laboratory Correlation Exercise (ILCE_LD) Final Report. European Commission Joint Research Centre Institute for Environment and Sustainability, 2007. 
40. Karavalakis, G., Short, D., Chen, V., Espinoza, C. et al., "Evaluating Particulate Emissions from a Flexible Fuel Vehicle with Direct Injection when Operated on Ethanol and Iso-butanol Blends," SAE Technical Paper 2014-01-2768, 2014, https://doi.org/10.4271/2014-01-2768.

41. Muñoz M, Heeb NV, Haag R, Honegger P, Zeyer K, Mohn J, Comte P, Czerwinski J. Bioethanol Blending Reduces Nanoparticle, PAH, and Alkyl- and Nitro-PAH Emissions and the Genotoxic Potential of Exhaust from a Gasoline Direct Injection Flex-Fuel Vehicle. Environmental Science \& Technology. 2016;50:11853-61.

42. Wei H, Zhu T, Shu G, Tan L, Wang Y. Gasoline engine exhaust gas recirculation - A review. Applied Energy. 2012;99:534-44.

43. Leach F, Stone R, Fennell D, Hayden D, Richardson D and Wicks N. "Predicting the particulate matter emissions from spray-guided gasoline direct-injection spark ignition engines". Proceedings of the Institution of Mechanical Engineers, Part D: Journal of Automobile Engineering. Vol 231, Issue 6, pp. 717 - 730. doi:10.1177/0954407016657453.

44. Leach, F., Stone, R., and Richardson, D., "The Influence of Fuel Properties on Particulate Number Emissions from a Direct Injection Spark Ignition Engine," SAE Technical Paper 2013-01-1558, 2013, https://doi.org/10.4271/2013-01-1558.

45. Litzinger T, Stoner M, Hess H, Boehman A. Effects of oxygenated blending compounds on emissions from a turbocharged direct injection diesel engine. International Journal of Engine Research. 2000;1:57-70. 